\title{
A Study of Efficiency Eccentric Drilling-Milling Chuck
}

\author{
Hasan Al Dabbas
}

\begin{abstract}
The articles describe the design and results of study of specifications of a drill and milling chuck.

The results of the study eccentric chuck rounds with the key in static and during cutting. A feature of the chuck used in manual, pneumatic and electric drills drilling, CNC milling, multi-purpose, woodworking and other machines, the existence of two kinematics chains, it possible to obtain high gain and reinforce the rigidity of the cutting tool with a cylindrical shank. This demonstrates the effectiveness of their use in the Machine-assembling manufacture.

Eccentric drilling and milling chuck designed for fast and secure clamping tools with cylindrical shank (drills, countersinks, reamers, milling cutters, etc.) right and left but self-rotation within specified range and other multi-purpose machines. Chuck design is to provides fast replacement tool, accuracy, durability, and reliable clamping of the hand or a key on a principle of self-locking chucks efficiently and conveniently used in surgical operations - for opening holes in the bones, that require low weight and dimensions as well as the reliability of fixation drill or other tool with quick changeover to another clamp diameter.
\end{abstract}

Index Terms-Eccentric drilling-milling chuck, metal-cutting machine, radial clamping force, clamping stiffness, eccentric tool clamping chuck.

\section{INTRODUCTION}

Actually, Twenty-century atheist and the third millennium marked a qualitative leap in production, steel count rightfully new high-tech and therefore the greatest success reaches a country where more and more applications are advances in science and technology [1], [2].

Despite the fact that in the field of metal in the manufacture of various equipment, a significant proportion of work (up to $50-70 \%$, and sometimes more), are in the development and manufacturing of industrial equipment, insufficient attention to research development, manufacture and introduction of competitive which allows to increase technical and economic parameters and expand the technological capabilities of metal and woodworking equipment.

Objectively, there is such situation, when continuous improvement of the structure of machine tools in general instrumental and technological equipment, is far behind keeping the traditional long (sometimes-secular) performance [3].

Providing the required clamping force of the clamping mechanism is now necessary condition but is not sufficient, due to the increased flexibility of quickset automated production that requires wide-blandness and quick regulating

Manuscript received May 23, 2014; revised August 15, 2014.

Hasan Al Dabbas is with Philadelphia University, Jordan (e-mail: drdabbas@engineer.com). of the clamping mechanisms, in particular, chuck engineering or chucks, during the time that maintaining the accuracy, rigidity, durability and stability characteristics [4].

\section{ECCENTRIC DRILLING-MiLLING CHUCK}

The chuck structure provides quick replacement of the tools, accuracy, durability and reliable gripping manually or with wrench as per self-retention principle.

If customer requires, eccentric chucks may be manufactured with different spindle connections internal or external Morse cone, thread, external self-holding taper 7:24, etc.

Eccentric tool clamping chucks differ from their known analogues in mode of functioning (two kinematic chains) [5]. Small weight and dimensions, reliability of structure consisting of five parts, and have the following advantages:

- Eccentric tool clamping chucks with two or more kinematic chains provide the best approved by results of pilot research of the chucks with two kinematic chains "key eccentric chuck" and amplifying circuit from additional drive cam with cylindrical generate [6] (Fig. 1).

- Possibility of processing of hart-to-reach places, through small dimensions and sharp conical front edge that smoothly transforms from the body to the cam and from the latter to the tool, modular principally of chuck design enabling to assemble chucks with different head pieces (inside or external Morse taper, bayonet lock, shank with a Morse taper or non-self-locking taper $7 \times 24$, thread hole or shank) from a limited set of parts [7].

- Quick gripping - releasing manually or with hex male drive wrench.

- Convenient and reliable work on left-hand and right-hand rotation of the tool locked.

- Wide range of the tools locked (essentially from zero to maximum diameter of the chuck).

- Accurate and reliable gripping of the tools;

- Simple manufacturing of the chuck parts, except cams ("know-how"), by mechanical treatment on metal-cutting machines, accurate casting, molding (die and cold) calibration, pressing or agglomeration of powders, etc.

- Operation at high-frequency rotation (by 2 or 3 times higher more than the analogues) [8], [9].

- Simple assembly-disassembly and maintenance.

- Durability and available quick replacement of worn-out parts.

- Available treatment of hard-to-get-to areas through small dimensions and sharp cone front end flowing from the body to the cam, and then to the tool.

- Modular design allowing assembly of the chucks with different connection parts from restricted set of parts

- Broad generality and unrestricted range of use (in industry and in day life) [10], [11]. 


\section{DESIGN STRUCTURE}

Eccentric with two and more kinematic chains provide the best cost-performance ratio that is confirmed by the results of experimental studies of with two kinematic chains "wedge eccentric cam" and strengthening unit from additional eccentric with a cylinder form (Fig. 1). The chuck the body (Fig. 2) has three eccentric clamping cams 4 toward to its axis Each one may turn toward to cylindrical slides that are evenly located on a circle and are spring-loaded to enable free release (opening of work hole for a shank of a cylindrical tool) with a ring spring 5 having bent edges and that is installed in a cylindrical groove of the chuck body [12].

Thread nut 3 with a conic whole (flared sleeve) is screwed onto three thread inserts 2 located in longitudinal slots of body and connected with it via eccentrics 6 the several that correspond to many of inserts 2 , the latter are held in the taper with a snap ring 7 .

The chuck works in two stages: stage 1 is a selection of the space between eccentric clamping cams 4 , and cylindrical shank of the tool, with a previous clamp, by rotation of thread nut 3 with a conic hole at an angle $\alpha^{\prime}$, stage 2 is a final clamping of the tool due to a system reload with a help of rotation of a wrench, e.g. a hex wrench one eccentric 6 , that additionally tightens a flared sleeve 3 to create a necessary clamping force [13], [14].

To determine the total radial clamping forces of three cams on stages 1 (T1) and two (T2) a collet dynamometer with tarred grips was used (Fig. 3).

In order to imitate a circumferential force applied to the wrench the disc weights (Fig. 3) of $1 \mathrm{~kg}(10 \mathrm{~N})$ used.

The experiment for each force $P$ repeated three times and mean value was calculated. The results of study of a force characteristic of the chuck showed (Fig. 5) that the mean coefficient of strengthening of the chuck was:

$$
K n=\frac{T_{\Sigma}}{P} \approx 100
$$

That made the work with a manual clamp easier.

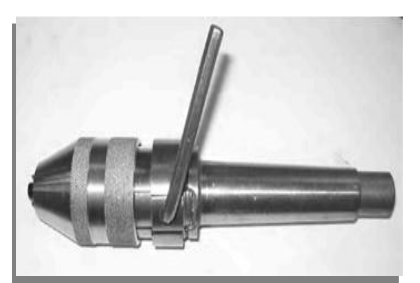

Fig. 1. Wide-range eccentric chuck with key (general view).

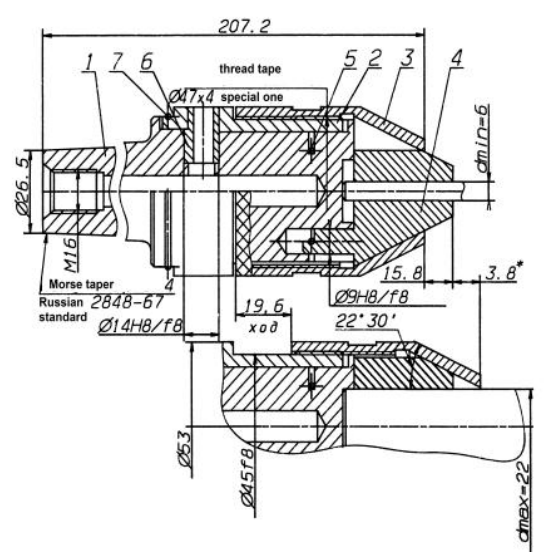

Fig. 2. Wide-range eccentric chuck with key (structure)
Thus, the proposed design working in two stages contains at least according to the steps of the kinematic chain 2 (Fig. 1).

1) For sample clearance and reload from rotating taper bushing 3 point (circumferential force), that converts the rotation about the fixed threaded inserts with two circumferential force in the axial movement of taper bushing, acting on a conical surface.

Eccentric clamping jaws 4, which turning relative to the cylindrical slider, creates a preliminary radial clamping force $\mathrm{T} 1$; 2) For turning the reload system using a key that generates torque force from the ring on its shoulder, that is because of the eccentric 6 diameter eccentricity e of the county force axial force develops transmitted through the threaded inserts tapered sleeve 2, 3 provides the last tool holder with additional radial force $\mathrm{T} 2$.

As a result, the total force tool clamping jaws shall be three: When clamping tool of various diameters for eccentric cams 3) Differently in get in touch with the tool and the cone sleeve, that leads to a change in power characteristics and elastic - the stress clearly of the interacting elements.

\section{EXPERIMENTAL PROCEDURE}

There are three eccentric chuck jaws 4 installed in the body of chuck 1 (drawing 2) and available for rotation relatively to cylindrical sliding bars, that are evenly situated on the circular curve and have beaded ring spring 5 installed in cylindrical groove of body 1 .

Threaded nut 3 , that tapered hole has $\alpha=22^{\circ} 30^{\prime}$ angle, shall be screwed on three thread inserts 2 located in the longitudinal grooves and connected with it through drive cams 6 , that number corresponds to the several inserts 2 held by snap ring 7 in the cone.

The chuck operates in two stages:

Adjustment of clearance between eccentric chuck jaws 4 , and cylindrical shank of the tool with pre-locking at rotation of the treaded nut 3; final locking of the tool through interference by the wrench turn, e.g. hexagonal wrench, of one or three drive jaws 6 additionally tightening flared sleeve 3 to get required chucking effect.

Collet dynamometer calibrated in the grip (Fig. 2) used to determine summary radial force $\mathrm{T}_{\Sigma}$ of gripping with three jaws.

Disc weights (Fig. 4) of $10 \mathrm{~N}$ used to imitate circumferential force $P$ applied to the wrench. The test repeated three times at each force value and the average value was calculated.

Results of the inspection force attributes of the chuck revealed (Fig. 5) that amplification ratio of chuck is $k_{n}=T_{\Sigma}$ $/ P \approx 100$, thus help operation on manual locking.

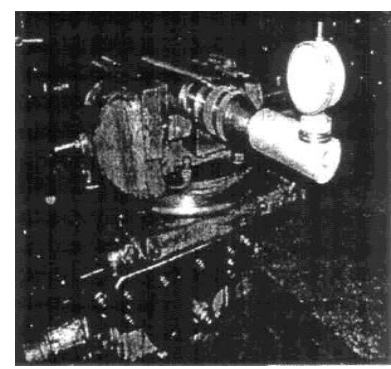

Fig. 3. Calibration of collet dynamometer. 
Radial stiffness of the jaw was determined on output load $58 \mathrm{~mm}$ of locked internal tools of $10,15,20 \mathrm{~mm}$ diameter with the use of loading device through tuning-fork load meter (Fig. 5) and measuring of pressing with the use of indicator having $0.01 \mathrm{~mm}$ scale length.

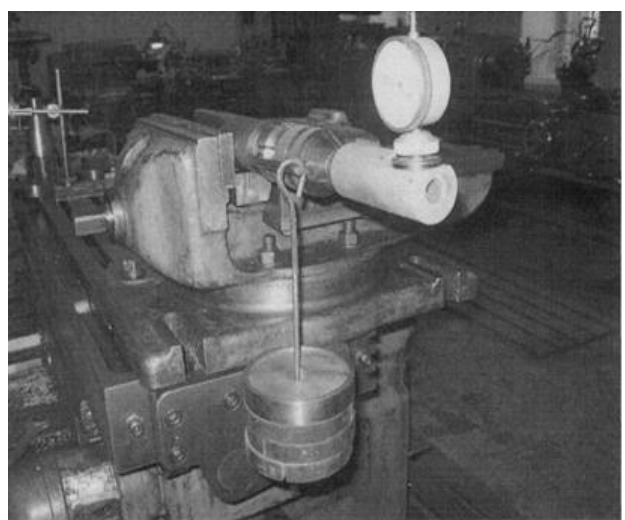

Fig. 4. Device with hinged balance weight to make circumferential force.

Fig. 4 measuring radial clamping force collet dynamometer in clumping chuck to determine the clamping force used $T \Sigma$ collet dynamometer sandwiched in drilling, milling chuck Clamped in a collet dynamometer drilling, milling chuck without clamping jaws chuck key and indicator readings obtained (Fig. 3), also The balancing system is designed to balance tool holders [15].

Drilling, milling chuck clamped in a vise mounted on the edge of the table vertical milling machine to be mounted on clamping knob (key) weights and loading goods from 1 to $10 \mathrm{~kg}$ (Weight one load $)=1 \mathrm{~kg}$. Drilling and milling cutting processes are extensively used for producing riveted and bolted joints during the assembly operation of composite laminates with other components [16].

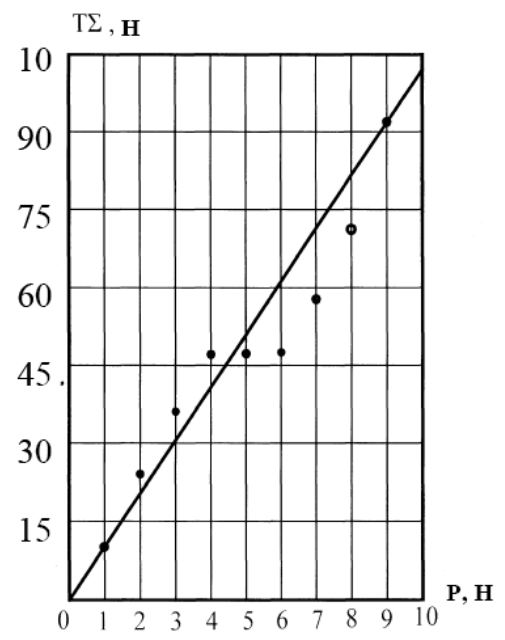

Fig. 5. Graph of radial chucking effect.

Fig. 5 Graph of Summary Radial Chucking produces an effect $T_{\Sigma}$ against Circumferential Force $P$ Applied to the Loading and unloading on the mandrel, done by moving the machine table (Fig. 5), loaded in accordance with the data of the calibration of the dynamometer. For each mandrel diameter $d=10 \mathrm{~mm}, d=15 \mathrm{~mm}, d=20 \mathrm{~mm}$ experiment was repeated 3 times and determined the average stiffness.

The results of measurements, calculations of system stiffness and wrung the graphs.

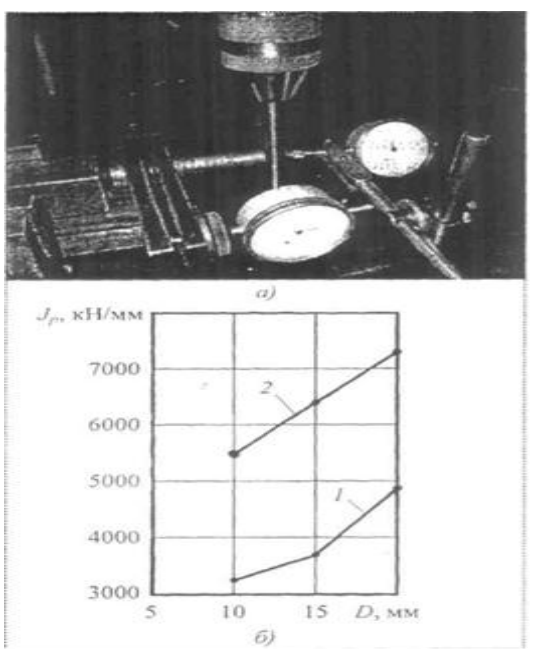

Fig. 6. Radial pressing tool.

Fig. 6 Measuring of Radial Pressing of Internal Tool Locked in Chuck, and Graph of Radial Stiffness of "Internal Tool - Chuck - Spindle" System on Outlet $58 \mathrm{~mm}$ Against Diameter D of Internal Tool at Summary Chucking result in $T \Sigma$ : $1-3.86 \mathrm{kN} 2-6.18 \mathrm{kN}$.

A radial press for work pieces with cylindrical outer surfaces, comprising, a plurality of pressing jaws arranged in a circle for radial movement toward the axis of a work piece outer surface, each jaw having outer surfaces, composed of surface parts, whose generatrices extend at two different angles other than 90 degrees relative to the axis of a work piece; a pressure ring having an inner surface composed of surface parts, the generatrices of which extend at two different angles other than 90 degrees relative to the axis.

\section{CONClusions}

Analysis of experimental results showed stiffness characteristics of the Chuck (Fig. 6) that an increase in the diameter of the tool shank $\mathrm{d}$ and total radial clamping force $T \Sigma$ radial stiffness increases. with increasing diameter of 2-fold (from $10 \mathrm{~mm}$ to $20 \mathrm{~mm}$ ) with $6.18 \mathrm{kN}=T \Sigma$ radial stiffness is increased by $33 \%$, and increase the clamping force is about 1.6 times of the diameter $d=10 \mathrm{~mm}-70 \%, d=$ $20 \mathrm{~mm}-52 \%$. This indicates that we need to increase the clamping force tool working at higher cutting conditions. In the future, the machining processes done with defined cutting edge (drilling, CNC milling, turning) used along with abrasive methods and non-conventional techniques.

\section{ACKNOWLEDGMENT}

Author would like to thank the presidency of Philadelphia University for encouragement of research and researchers at the university, also author would like to thank the deanship of Engineering Faculty, finally thanks are due the scientific research committee and deanship of scientific research at Philadelphia University.

\section{REFERENCES}

[1] V. E. Pusch, R. Pigert, and V. L. Sosonkin, Automatic Machine Tools Engineering, 1982, p. 319.

[2] A. I. Polovinkin, N. K. Bobkov, and G. Y. Bush, Automating Exploratory Design (Artificial intelligence in the Engine Design), 1981, p. 344. 
[3] J. N. Kuznetsov, O. L. Gumenyuk, A. M. Rudkovsky, and H. Al-Dabbas, "Manufacturing principle of tool sensitive clamping chucks for high-velocity processing 3b," Scientific Works of Kirovograd National Technical University, vol. 17. pp. 134-141, 2006.

[4] J. N. Kuznetsov, A. A. Vachev, S. P. Syarov, and A. J. Tservenkov, Under, Self-adjusting Clamping Devices, Engineering state editor office, 1988, p. 222.

[5] J. N. Kuznetsov, P. M. Nedelcheva, and H. Al-Dabbas, "Study for the chuck stiffness features of eccentric milling chucks," in Proc. International Scientific and Technical Conference "Unitech'06", Gabrovo, 2006, pp. 131-152.

[6] J. N. Kuznetsov, H. Al-Dabbas, and P. M. Nedelcheva, "Computer generated simulation and study for main characteristics of eccentric drilling-milling chuck," Machines Technologies, Materials, vol. 2, pp. 35-38, 2007.

[7] J. N. Kuznetsov, P. M. Nedelcheva, and H. Al-Dabbas. "System-and-Structural approach on synthesis of wide-range eccentric drilling-milling chucks," News from Technical University, Gabrovo, vol. 33, pp. 3-8, 2006.

[8] J. N. Kuznetsov, H. Al-Dabas, P. M. Nedelcheva, "Computer simulation study of power and the characteristics of the eccentric chuck," Design, Manufacture and Operation of Agricultural Machinery, Kirovograd, pp. 247-252, 2006

[9] J. N. Kuznetsov, P. M. Nedelcheva, and K. Lunev, "Application of genetic operators in the synthesis of collet," in Proc. International Scientific Conference of UNITEH'09', TU. Gabrovo, 2009, pp. 99-102.

[10] J. N. Kuznetsov, H. Gerra, and A. Popanov, "Genetic-morphological approach to creating and forecasting the development of clamping mechanisms for rotating parts," Journal of the Technical Uuniversity Sofia, Bulgaria Fundamental Sciences and Aapplications, vol. 19, 2013.

[11] H. A. Razavi, T. R. Kurfess, and S. Danyluk, "Force control grinding of gamma titanium aluminide," International Journal of Machine Tools \& Manufacture, vol. 43, no. 2, pp. 185-191, 2003.
[12] A. R. C. Sharman, D. K. Aspinwall, R. C. Dewes, D. Clifton, and P. Bowen, "The effects of machined work piece surface integrity on the fatigue life of $\gamma$-titanium aluminized," International Journal of Machine Tools and Manufacture, vol. 41, no. 11, pp. 1681-1685, 2001.

[13] F. K. Koenigsberger and A. J. P. Sabberwal, "An investigation into the cutting force pulsations during milling," International Journal of Machine Tool Design and Research, vol .1, no. 1, pp. 15-33, 1961.

[14] Z. H. Zhang, L. Zheng, L. Zhang, Z. Z. Li, D. C. Liu, and B. P. Zhang, "A study on calibration of coefficients in end milling forces model," The International Journal of Advanced Manufacturing Technology, vol. 25, no. 7, pp. 652-662, 2005.

[15] J. N. Kuznetsov, H. Al-Dabbas, and H. Guerra, "Genetic morphological approach to creating wide range drilling-milling chucks," International Journal of Sciences: Basic and Applied Research, vol. 13, no. 1, 2014.

[16] H. M. Ali, A. Iqbal, and L. Liang, "A comparative study on the use of drilling and milling processes in hole making of GFRP composite," Sadhana, vol. 38, no. 4, pp. 743-760, 2013.

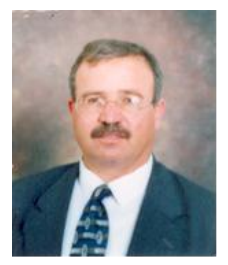

Hasan Al Dabbas is presently an assistant professor at the Mechanical Engineering Department at Philadelphia University, Jordan. He earned his PhD in 2011, in engineering science (technology and equipment of mechanical and physical technical treatment). He received his MSc in 1997 in engineering science (high effective process of treatment). He was appointed as a cultural counselor for Jordan Embassy in Russian Federations. Dr. Aldabbas published several books in engineering drawing. 